\title{
A Facile Route to Synthesizing Functionalized Mesoporous SBA-15 Materials with Platelet Morphology and Short Mesochannels
}

\author{
Shih-Yuan Chen, ${ }^{\dagger}$ Chih-Yuan Tang, ${ }^{\ddagger}$ Wei-Tsung Chuang, ${ }^{\S}$ Jey-Jau Lee, ${ }^{\S}$ Yi-Ling Tsai, ${ }^{\dagger}$ \\ Jerry C. C. Chan, ${ }^{\dagger}$ Ching-Yen Lin, ${ }^{\ddagger}$ Yu-Cheng Liu,,$"$ and Soofin Cheng*, ${ }^{*}$ \\ Department of Chemistry and Instrumental Center, National Taiwan University, Taipei 106, Taiwan, \\ Research Division, National Synchrotron Radiation Research Center, Hsinchu 300, Taiwan, and \\ Department of Raw Materials and Yarn Formation, Taiwan Textile Research Institute, \\ Taipei County 236, Taiwan
}

Received December 8, 2007. Revised Manuscript Received February 29, 2008

\begin{abstract}
A facile synthesis route for preparing SBA-15 silica of platelet shape and very short mesochannels $(150-350 \mathrm{~nm})$ was developed by introducing a small amount of $\mathrm{Zr}(\mathrm{IV})$ ions in the synthesis solution. The synthesis route can be easily extended to prepare platelet SBA-15 materials with various organic functional groups up to $1.87 \mathrm{mmol} / \mathrm{g}$ loading in one pot. In situ XRD and freeze-fracture replication TEM were found to be powerful techniques for studying the self-assembly processes. The platelet SBA15 with short mesochannels in $150-350 \mathrm{~nm}$ was formed because of the fast self-assembly rate of P123 micelles and TEOS accelerated by the $\mathrm{Zr}$ (IV) ions in the synthesis solution. The platelet SBA-15 materials are superior to the conventional SBA-15 of rod or fiber morphologies in facilitating molecular diffusion and less possibility of pore blockage when used in the sorption or reactions of bulky molecules.
\end{abstract}

\section{Introduction}

Mesoporous silica materials of high surface areas and wellordered pore structures have potential applications in separation, catalysis, microelectronic device, and enzyme immobilization. ${ }^{1-4}$ SBA-15 material of two-dimensional channeling pores arranged in hexagonal $p 6 \mathrm{~mm}$ structure has received great attention because of its relatively large pore and high hydrothermal stability in comparison to MCM-41, its analog in M41S family. ${ }^{5,6}$ The diameter of the channeling pores of SBA-15 can be varied in $3-10 \mathrm{~nm}$, whereas the length is usually in the scale of micrometers. Molecular diffusion through the lengthy mesochannels and pore blockage along the channels are the main concern when applying these materials for sorption and catalysis. Several papers have unveiled the preparation of pure siliceous SBA-15 materials

* Corresponding author. Fax: 886-2-23636359. Tel: 886-2-33661662. E-mail: chem1031@ntu.edu.tw.

Department of Chemistry, National Taiwan University.

Instrumental Center, National Taiwan University.

$\$$ National Synchrotron Radiation Research Center.

"Taiwan Textile Research Institute.

(1) (a) Feng, X.; Fryxell, G. E.; Wang, L. Q.; Kim, A. Y.; Liu, J.; Kemner, K. M. Science 1997, 276, 92. (b) Brown, J.; Mercier, L.; Pinnavaia, T. J. Chem. Commun. 1999, 69.

(2) (a) Corma, A. Chem. Rev. 1997, 97, 237. (b) Wang, X.; Chen, C. C.; Chen, S. Y.; Mou, Y.; Cheng, S. Appl. Catal., A 2005, 281, 47. (c) Crudden, C. M.; Sateesh, M.; Lewis, R. J. Am. Chem. Soc. 2005, 127, 10045.

(3) (a) Baskaran, S.; Liu, J.; Domansky, K.; Kohler, N.; Li, X.; Coyle, C.; Fryxell, G. E.; Thevuthasan, S.; Williford, R. E. Adv. Mater. 2000, 12, 291. (b) Wang, Y.; Yang, C. M.; Schmidt, W.; Spliethoff, B.; Bill, E.; Schü th, F. Adv. Mater. 2005, 17. (c) Yang, P. D.; Wirnsberger, G.; Huang, H. C.; Cordero, S. R.; McGehee, M. D.; Scott, B.; Deng, T.; Whitesides, G. M.; Chmelka, B. F.; Buratto, S. K.; Stucky, G. D. Science 2000, 287, 465.

(4) (a) Lu, A. H.; Schuth, F. C. R. Chim. 2005, 8, 609. (b) Han, Y.; Lee, S. S.; Ying, J. Y. Chem. Mater. 2006, 18, 643. (c) Tian, R.; Zhang, H.; Ye, M.; Jiang, X.; Hu, L.; Li, X.; Bao, X.; Zou, H. Angew. Chem., Int. Ed. 2007, 46, 962 . with short mesochannels in the submicrometer level by adding either cosurfactant, cosolvent, electrolytes, or organosilanes into the synthesis solutions. ${ }^{7-17}$ For example, Han and Ying ${ }^{13}$ have reduced the particle size of mesoporous silica to $50-300 \mathrm{~nm}$ under a weak acidic synthesis condition using a mixture of triblock copolymer and cationic fluorocarbon surfactant. In other cases, $\mathrm{NH}_{4} \mathrm{~F}$ was added in addition to a cosolvent such as decane or octane to synthesize siliceous SBA-15 of cuboid or flake morphology with mesochannels in submicrometers. ${ }^{9,14}$ The cosolvents and fluorocarbon surfactant were proposed to surround the silica particles and thereby limited the aggregation and growth of silica particles. However, these methods may not be ap-

(5) (a) Kresge, C. T.; Leonowicz, M. E.; Roth, W. J.; Vartuli, J. C.; Beck, J. S. Nature 1992, 359, 710. (b) Beck, J. S.; Vartuli, J. C.; Roth, W. J.; Leonowicz, M. E.; Kresge, C. T.; Schmitt, K. D.; Chu, C. T.-W.; Olson, D. H.; Sheppard, E. W.; McCullen, S. B.; Higgins, J. B.; Schlenker, J. L. J. Am. Chem. Soc. 1992, 114, 10834.

(6) (a) Zhao, D.; Feng, J.; Huo, Q.; Melosh, N.; Fredrickson, G. H.; Chmelka, B. F.; Stucky, G. D. Science 1998, 179, 548. (b) Zhao, D.; Huo, Q.; Feng, J.; Chmelka, B. F.; Stucky, G. D. J. Am. Soc. Chem. 1998, 120,6024 .

(7) Konya, Z.; Zhu, J.; Szegedi, A.; Kiricsi, I.; Alivisatos, P.; Somorjai, G. A. Chem. Commun. 2003, 314.

(8) Fan, J.; Lei, J.; Wang, L.; Yu, C.; Tu, B.; Zhao, D. Chem. Commun. 2003, 2140.

(9) Zhang, H.; Sun, J.; Ma, D.; Bao, X.; Klein-Hoffmann, A.; Weinberg, G.; Su, D.; Schlogl, R. J. Am. Chem. Soc. 2004, 126, 7440.

(10) Chen, S. Y.; Jang, L. Y.; Cheng, S. Chem. Mater. 2004, 16, 4174.

(11) Chen, B.-C.; Lin, H.-P.; Chao, M.-C.; Mou, C.-Y.; Tang, C.-Y. Adv. Mater. 2004, 16, 1657.

(12) Shan, W.; Wang, B.; Zhang, Y.; Tang, Y. Chem. Commun. 2005, 1877.

(13) Han, Y.; Ying, J. Y. Angew. Chem., Int. Ed. 2005, 44, 288.

(14) Sun, J. M.; Zhang, H.; Tian, R. J.; Ma, D.; Bao, X. H.; Su, D. S.; Zou, H. F. Chem. Commun. 2006, 1322.

(15) Sujandi.Park, S. E.; Han, D. S.; Han, S. C.; Jin, M. J.; Ohsuna, T. Chem. Commun. 2006, 4131.

(16) Cui, X.; Moon, S.-W.; Zin, W.-C. Mater. Lett. 2006, 60, 3857.

(17) Kipkemboi, P.; Fogden, A.; Alfredsson, V.; Flodstrom, K. Langmuir 2001, 17, 5398. 
plicable to prepare organic functionalized materials in one pot because of the interference of the cosolvents in the selfassembly process and the reactivity of $\mathrm{NH}_{4} \mathrm{~F}$ toward organosilanes. Among the literature up to now, only one of them described the preparation of amino-functionalized mesoporous SBA-15. ${ }^{15}$ Nevertheless, the method was limited to preparing SBA-15 silica with a narrow amino-loading. The incorporation of organic functional groups is important in the applications of mesoporous silica. Here, we report a facile synthesis route for preparing SBA-15 silica of platelet shape and very short mesochannels $(150-350 \mathrm{~nm})$. Moreover, the synthesis route can be easily extended to prepare platelet SBA-15 materials with various organic functional groups up to $1.87 \mathrm{mmol} / \mathrm{g}$ loading in one pot. The self-assembly processes were examined by the in situ XRD and freezefracture replication TEM techniques. The advantages of the resultant materials were demonstrated by the faster adsorption rates and larger adsorption capabilities toward bulky organic molecules, in comparison to the conventional SBA-15.

\section{Experimental Methods}

Synthesis. Conventional SBA-15 of rod-shape was prepared by dissolving $1.00 \mathrm{~g}$ of Pluronic P123 triblock copolymer (Aldrich, $\left.M_{\mathrm{n}}=5800\right)$ in $40.0 \mathrm{~g}$ of $2 \mathrm{M} \mathrm{HCl}$ solution at $35^{\circ} \mathrm{C}$, followed by adding $2.10 \mathrm{~g}$ of TEOS (Acros 98\%). The reactant compositions were 0.017:1:7.94:221 P123:TEOS: $\mathrm{HCl}: \mathrm{H}_{2} \mathrm{O}$. The mixture was sealed in a polypropylene bottle, stirred at $35^{\circ} \mathrm{C}$ for $24 \mathrm{~h}$, and then hydrothermally heated at $90{ }^{\circ} \mathrm{C}$ under static conditions for another $24 \mathrm{~h}$. The solid product was filtered, washed with deionized water, and dried at $50{ }^{\circ} \mathrm{C}$ overnight. The $\mathrm{P} 123$ templates were removed by calcining the material at $500{ }^{\circ} \mathrm{C}$ in air for $12 \mathrm{~h}$ with a ramping rate of $1{ }^{\circ} \mathrm{C} / \mathrm{min}$. Platelet SBA- 15 was prepared by adding a small amount of $\mathrm{Zr}(\mathrm{IV})$ ions in the conventional SBA-15 synthesis solution. The reactant compositions were 0.017:1:0.03-0.1:7.94: $221 \mathrm{P} 123: \mathrm{TEOS}: \mathrm{ZrOCl}_{2} \cdot 8 \mathrm{H}_{2} \mathrm{O}: \mathrm{HCl}: \mathrm{H}_{2} \mathrm{O}$.

Platelet SBA-15 materials functionalized with 5-30 mol\% organic functional groups were prepared by one-pot method. Prior to the addition of the organosilane, TEOS was prehydrolyzed in the synthesis solution containing $\mathrm{HCl}, \mathrm{P} 123$ and $\mathrm{Zr}(\mathrm{IV})$ ions for 1-4 h. P123 was removed by ethanol extraction at $78^{\circ} \mathrm{C}$ for 1 day.

Adsorption. The adsorption of new coccine (Arcos, $\mathrm{C}_{20} \mathrm{H}_{11} \mathrm{~N}_{2} \mathrm{Na}_{3} \mathrm{O}_{10} \mathrm{~S}_{3}, \mathrm{MW}=604.5 \mathrm{~g} / \mathrm{mol}$ ) was carried out by adding $50 \mathrm{mg}$ of the solid in $10 \mathrm{~mL}$ of new coccine solution $(0.0385 \mathrm{mM})$ under stirring at room temperature. After various periods, the solid was separated from the solution by filtration and the concentration of new coccine in the filtrate was determined by absorbance at 507 $\mathrm{nm}$.

Characterization. XRD patterns were recorded using a PANalytical diffractometer with $\mathrm{Cu}_{\mathrm{K \alpha}}$ radiation operated at $40 \mathrm{~mA}$ and $45 \mathrm{kV}$. The textural properties of samples were analyzed by nitrogen physical adsorption at liquid $\mathrm{N}_{2}$ temperature $(77 \mathrm{~K})$ using a Micromeritics Tristar 3000 instrument. Prior to the experiments, the samples were degassed at $120^{\circ} \mathrm{C}$ for more than $8 \mathrm{~h}$ under a vacuum $\left(1 \times 10^{-3}\right.$ Torr $)$. The specific surface areas were evaluated using Brunauer-Emmett-Teller (BET) method in the $P / P_{0}$ range of $0.05-0.3$. Pore size distribution curves were calculated using the desorption branch of the isotherms and the Barrett-JoynerHalenda $(\mathrm{BJH})$ method $^{18}$ and pore sizes were obtained from the

(18) Wang, X.; Lin, K. S. K.; Chan, J. C. C.; Cheng, S. J. Phys. Chem. B 2005, 109, 1763. peak positions of the distribution curves. The elemental contents in bulk were determined by inductive-coupled plasma-atomic emission spectroscopy (ICP-AES, ELAN 5000 instrument). The elemental analysis of $\mathrm{C}, \mathrm{H}, \mathrm{N}$, and $\mathrm{S}$ was measured by using a Heraeus VarioEL analyzer. The in situ XRD experiments were carried out at Beam line 17A of National Synchrotron Radiation Center (NSRRC) at Hsinchu, Taiwan. The wavelength of the X-ray source was $1.334431 \AA$. The gelled sample was pumped into a Teflon sample cell by using wriggle pump. The in situ XRD patterns were collected every 3 min using image plate detection. The TEM images of freeze-fracture replication (FFR) were performed using a Hitachi H-7100 Transmission Electron Microscope operating at $75 \mathrm{kV}$. The liquid sample was dropped in between two electron microscopy gold grids. The sandwiched sample was then frozen at liquid $\mathrm{N}_{2}$ temperature. The frozen sandwich was split in a Balzers freeze-fracture apparatus (BAF $400 \mathrm{D})$ and coated with a $\mathrm{Pt}-\mathrm{C}$ thin layer at $45^{\circ}$ angle, followed by coating another carbon layer at $90^{\circ}$. The replicas were received by throwing the coated sample in a HF solution. The scanning electron microscopy (SEM) images and energy-dispersed X-ray spectrometer (EDX) were taken on a Hitachi S-800 field-emission scanning electron microscope and S-2400 scanning electron microscope, respectively. The NMR experiments were carried out at ${ }^{29} \mathrm{Si},{ }^{13} \mathrm{C}$, and ${ }^{1} \mathrm{H}$ frequencies of 59.6, 75.5, and 300.1 MHz, respectively, on a Bruker DSX300 NMR spectrometer equipped with a commercial $7 \mathrm{~mm}$ MAS NMR probe with magic-angle spinning (MAS) frequencies setting at 5 $\mathrm{kHz}$ for all experiments. The chemical shifts were externally referred to tetramethylsilane for ${ }^{29} \mathrm{Si}$ and ${ }^{13} \mathrm{C}$. For the ${ }^{29} \mathrm{Si}$ Bloch-decay experiment, the recycle delay was set to $60 \mathrm{~s}$. The $\mathrm{Q}_{4} /\left(\mathrm{Q}_{2}+\mathrm{Q}_{3}\right)$ area ratios were obtained by deconvolution of the peaks in the spectra using WinFit software. ${ }^{13} \mathrm{C}\left\{{ }^{1} \mathrm{H}\right\}$ cross-polarization spectra were measured with a recycle delay of $4 \mathrm{~s}$, and the contact times were $1.5 \mathrm{~ms}$. During the contact time the ${ }^{1} \mathrm{H}$ nutation frequency was set equal to $50 \mathrm{kHz}$, and a linear ramping was applied to the nutation frequencies of ${ }^{13} \mathrm{C}(27.3-43.0 \mathrm{kHz})$. The proton decoupling field during the acquisition period was $83 \mathrm{kHz}$.

\section{Results and Discussion}

The platelet SBA-15 materials were prepared by adding small amounts of $\mathrm{Zr}(\mathrm{IV})$ ions $(\mathrm{Zr} / \mathrm{Si}=0.03-0.1)$ in the conventional SBA-15 synthesis solutions. The optimal molar compositions in the synthesis solution were 0.017:1:0.05: 7.94:221 P123:TEOS: $\mathrm{ZrOCl}_{2} \cdot 8 \mathrm{H}_{2} \mathrm{O}: \mathrm{HCl}_{2} \mathrm{H}_{2} \mathrm{O}$. Figure 1 shows the resultant siliceous SBA-15 has three distinct diffraction peaks at $2 \theta=0.90,1.52$, and $1.76^{\circ}$ indexed to the (100), (110), and (200) planes, respectively, of 2D hexagonal $p 6 \mathrm{~mm}$ symmetry $^{6}$ and a narrow pore size distribution with the peak pore diameter at $6.7 \mathrm{~nm}$. SEM photograph shows the materials are homogeneously dispersed hexagonal thin platelets. The average width and thickness of the platelets are $800-1100 \mathrm{~nm}$ and $150-300 \mathrm{~nm}$, respectively. Wellordered pores arranged in 2D hexagonal $p 6 \mathrm{~mm}$ structure and aligned along the thickness of the thin platelets are observed on the TEM photographs. In other words, the lengths of mesochannels are the thickness of the thin platelets, which are slightly thinner at the edge and thicker at the center. The platelet morphology and short mesochannels of these materials are quite different from those of conventional SBA-15, which possesses rod- or fiberlike morphology and long mesochannels in micrometers (see the Supporting Information). ${ }^{6}$ 

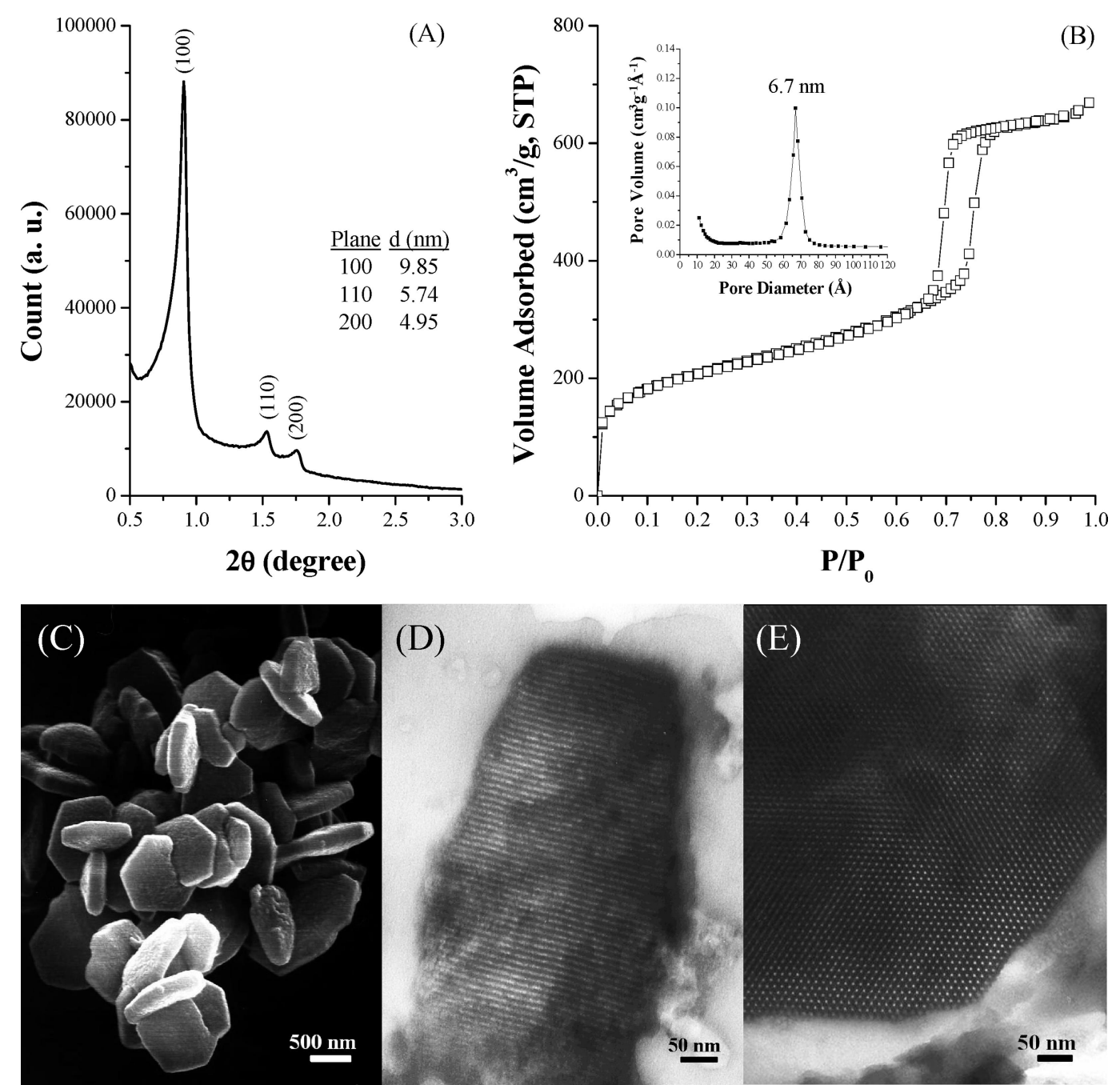

Figure 1. (A) Small-angle XRD pattern using $\mathrm{Cu}_{\mathrm{K} \alpha}$ radiation source $\left(\lambda=1.5418 \AA\right.$ ) , (B) $\mathrm{N}_{2}$ sorption isotherm, (C) SEM image, and (D, E) TEM images of calcined SBA-15 with platelet morphology and short mesochannels.

This new synthesis route could be easily extended to prepare organic functionalized SBA-15. Figure 2 shows the small-angle XRD patterns of the resultant SBA-15 materials with various organic functionalities, including $\mathrm{CH}_{3}, \mathrm{Ph}$, $\mathrm{Cl}\left(\mathrm{CH}_{2}\right)_{3}, \mathrm{SH}\left(\mathrm{CH}_{2}\right)_{3}, \mathrm{CN}\left(\mathrm{CH}_{2}\right)_{3}$, and $\mathrm{NH}_{2}\left(\mathrm{CH}_{2}\right)_{3}$ groups. Three distinct diffraction peaks indexed to the (100), (110), and (200) planes of 2D hexagonal $p 6 \mathrm{~mm}$ symmetry appear at $2 \theta \approx 0.7-2^{\circ}$. The positions of the diffraction peaks vary slightly for materials containing different organic groups, implying that the aggregation numbers of P123 micelles are affected by the organosilane precursors.

Figure 3 shows the EM photographs of the organic functionalized SBA-15. All the materials are still homogeneously dispersed hexagonal thin platelets. The thickness of the platelets of the functionalized SBA-15 is slightly thicker than that of pure siliceous SBA-15, but the channeling pores are still aligned along the height of the platelets (see the Supporting Information). The average thickness of the platelets are in $150-350 \mathrm{~nm}$.

The $\mathrm{N}_{2}$ sorption isotherms of the ethanol extracted platelet SBA-15 materials show the classical type IV isotherms with $\mathrm{H}_{1}$ hysteresis loops appeared at $P / P_{0} \approx 0.5-0.8$, depending on the functional groups (abbreviated as FG). The derived textural properties are shown in Table 1 . All the materials possess high surface area $\left(611-810 \mathrm{~m}^{2} / \mathrm{g}\right)$, large pore volume $\left(0.57-1.01 \mathrm{~cm}^{3} / \mathrm{g}\right)$, thick pore wall $(4.6-7.1 \mathrm{~nm})$, and large mesopores $(4.2-6.7 \mathrm{~nm})$ with narrow pore size distribution (PSD $<1.4 \mathrm{~nm}$ ), similar to those of conventional SBA-15 material. ${ }^{6}$ Moreover, the organic functionalized SBA-15 materials have smaller pore diameters but thicker pore walls than those of siliceous SBA-15, implying that the organic functional groups should be incorporated onto the silica framework. On the other hand, the pore diameters of the organic functionalized SBA-15 platelets vary with different organic groups, indicating that the aggregation numbers of P123 micelles are changed by the organic moieties of organosilanes.

It is also noticeable that the pore diameter of siliceous platelet SBA-15 is slightly larger than those of conventional siliceous fiber-shaped SBA-15, revealing that the average micellar radius of P123 micelles was increased in the presence of $\mathrm{Zr}(\mathrm{IV})$ ions. It is attributed to the so-called salting out effect that the hydrophobic core of P123 micelle is expanded as the hydrophilicity of the PEO chains decreases. ${ }^{19}$ As a result, the micropore area and volume determined by nitrogen physisorption are $202 \mathrm{~m}^{2} / \mathrm{g}$ and 0.091 

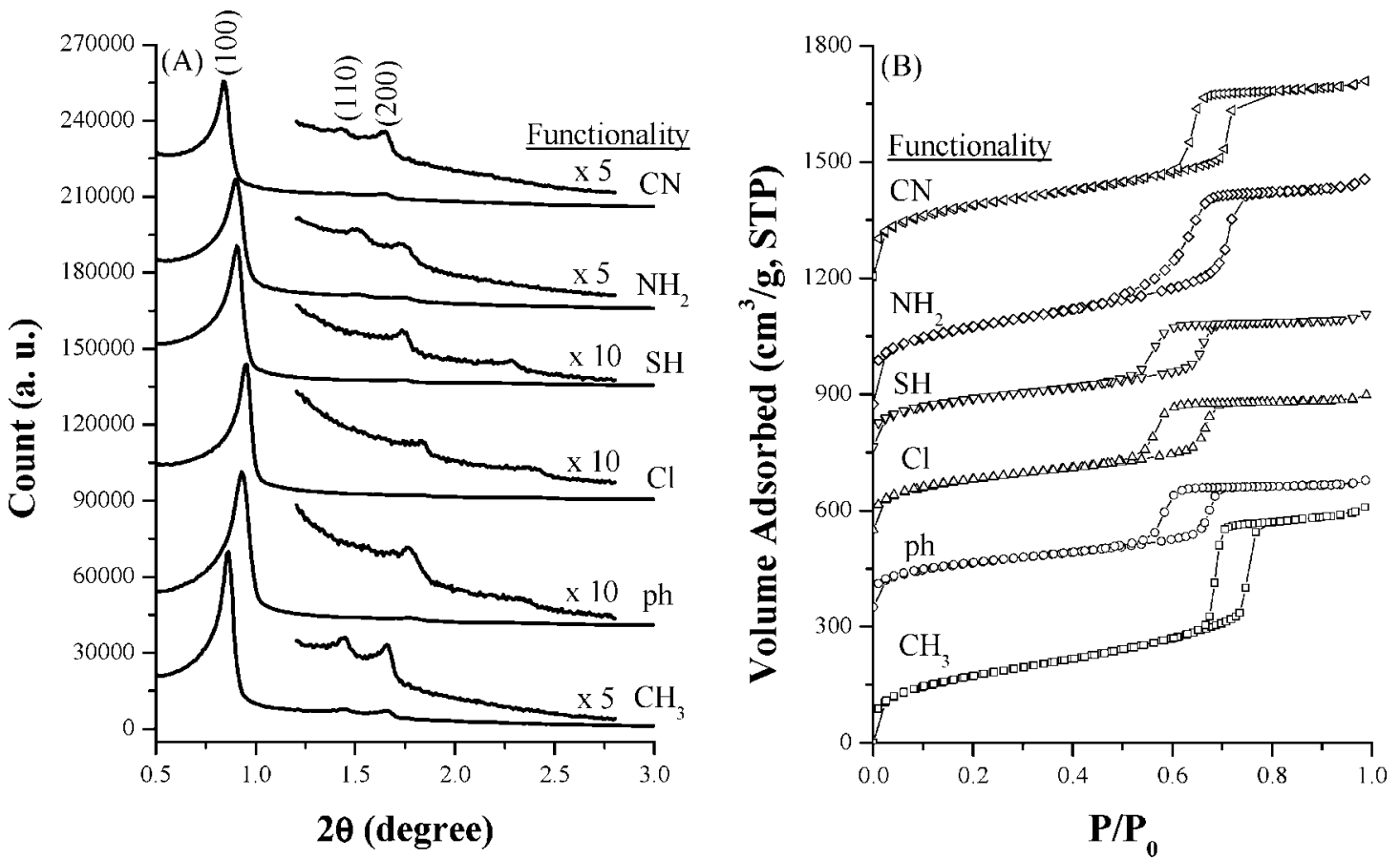

Figure 2. (A) Small-angle XRD patterns using $\mathrm{Cu}_{\mathrm{K \alpha}}$ radiation source $\left(\lambda=1.5418 \AA\right.$ ), (B) $\mathrm{N}_{2}$ sorption isotherms of extracted organic functionalized SBA-15 with platelet morphology and short mesochannels.
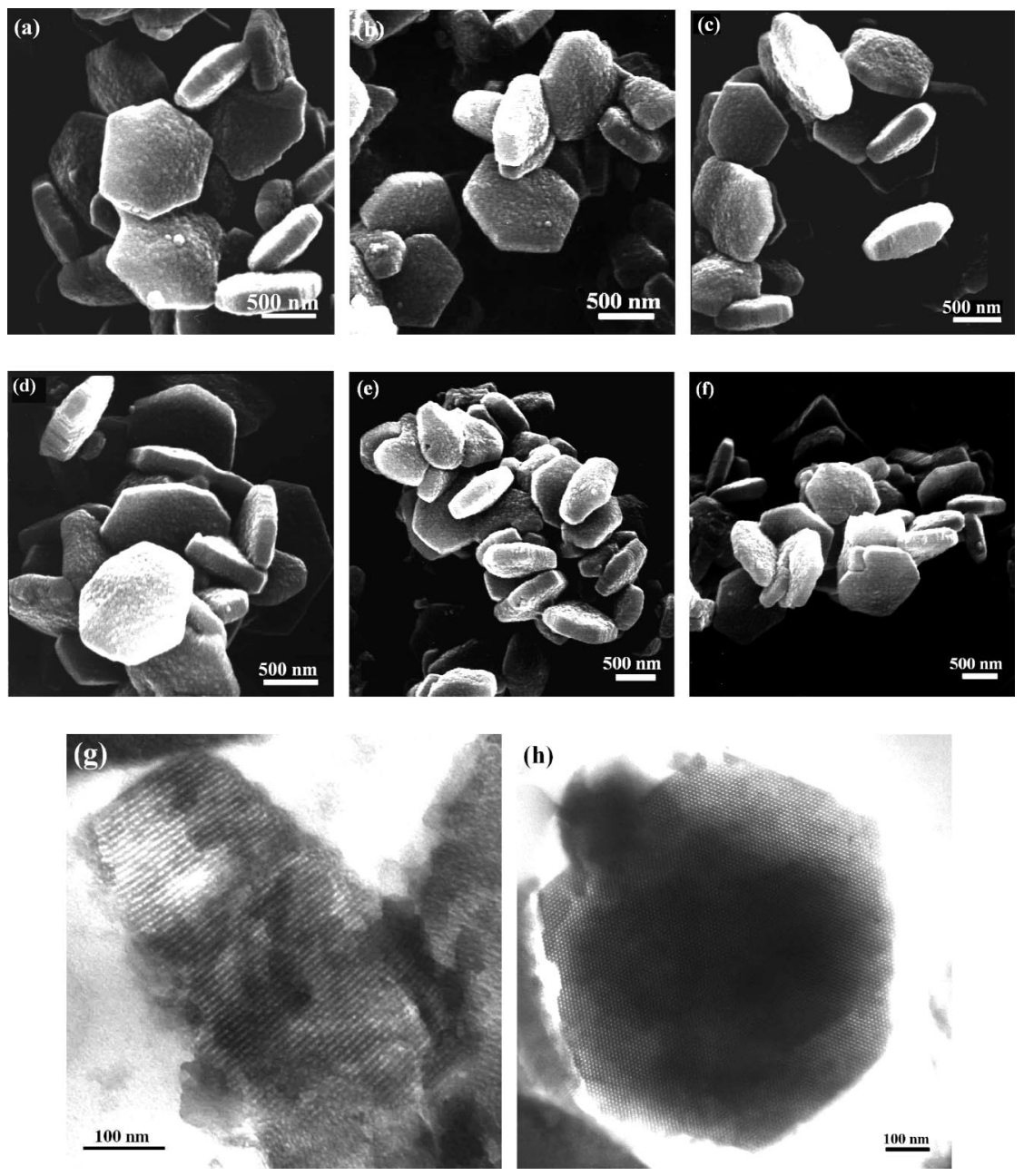

Figure 3. SEM and selected TEM images of various extracted organic functionalized SBA-15 with platelike morphology and short mesochannels (a) $\mathrm{CH}_{3}$, (b) $\mathrm{Ph}$, (c) $\mathrm{Cl},(\mathrm{d}, \mathrm{g}, \mathrm{h}) \mathrm{SH}$, (e) $\mathrm{NH}_{2}$, (f) $\mathrm{CN}$. 
Table 1. Elemental Analyses and Textural Properties of Extracted Organic Functionalized SBA-15 Platelets with Short Mesochannels

\begin{tabular}{|c|c|c|c|c|c|c|c|c|c|}
\hline \multirow[b]{2}{*}{ functionality } & \multirow[b]{2}{*}{$\mathrm{PT}^{a}(\mathrm{~h})$} & \multicolumn{2}{|c|}{ FG/Si } & \multirow[b]{2}{*}{$a_{0}(\mathrm{~nm})$} & \multirow[b]{2}{*}{$S_{\mathrm{BET}}\left(\mathrm{m}^{2} / \mathrm{g}\right)$} & \multirow[b]{2}{*}{$V_{\text {Total }}\left(\mathrm{cm}^{3} / \mathrm{g}\right)$} & \multirow[b]{2}{*}{$\Phi_{\mathrm{P}}^{c}(\mathrm{~nm})$} & \multirow[b]{2}{*}{$\operatorname{PSD}^{d}(\mathrm{~nm})$} & \multirow[b]{2}{*}{$W^{e}(\mathrm{~nm})$} \\
\hline & & gel & $\operatorname{solid}^{b}$ & & & & & & \\
\hline none & 0 & 0.091 & 0.034 & 11.3 & 732 & 1.01 & 6.7 & 0.8 & 4.6 \\
\hline $\mathrm{CH}_{3}$ & 1 & 0.091 & 0.096 & 11.9 & 810 & 1.00 & 6.4 & 0.8 & 5.2 \\
\hline $\mathrm{Ph}$ & 2 & 0.091 & 0.100 & 11.0 & 662 & 0.71 & 4.5 & 1.1 & 6.5 \\
\hline$\left(\mathrm{CH}_{2}\right)_{3} \mathrm{Cl}$ & 2 & 0.091 & 0.099 & 10.7 & 611 & 0.57 & 4.5 & 1.1 & 6.2 \\
\hline$\left(\mathrm{CH}_{2}\right)_{3} \mathrm{SH}$ & 2 & 0.091 & 0.086 & 11.3 & 616 & 0.57 & 4.2 & 1.2 & 7.1 \\
\hline$\left(\mathrm{CH}_{2}\right)_{3} \mathrm{NH}_{2}$ & 4 & 0.091 & 0.088 & 11.4 & 712 & 0.87 & 5.4 & 1.4 & 6.0 \\
\hline$\left(\mathrm{CH}_{2}\right)_{3} \mathrm{CN}$ & 1 & 0.091 & 0.100 & 12.2 & 744 & 0.82 & 5.5 & 1.2 & 6.7 \\
\hline
\end{tabular}

${ }^{a}$ Prehydrolysis period. ${ }^{b} \mathrm{FG} / \mathrm{Si}$ molar ratios are measured by CHNS elemental analysis. ${ }^{c}$ Pore diameter. ${ }^{d}$ Pore size distribution. ${ }^{e}$ Wall thickness.
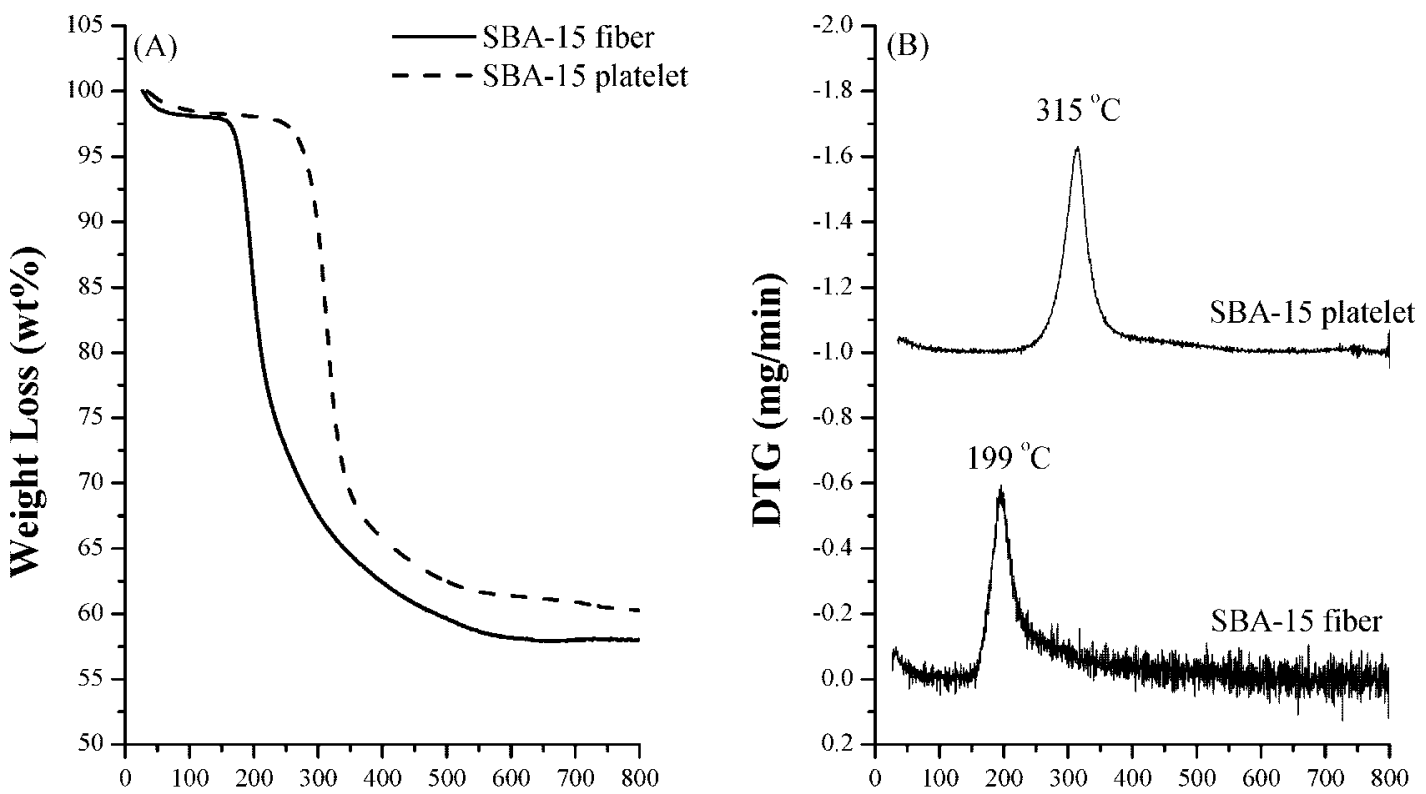

Temperature $\left({ }^{\circ} \mathrm{C}\right)$

Figure 4. (A) TG and (B) DTG profiles of as-made SBA-15 materials with conventional fiberlike and platelet morphologies.

$\mathrm{cm}^{3} / \mathrm{g}$, respectively, for siliceous fiber-shaped SBA-15, while those are lowered to $159 \mathrm{~m}^{2} / \mathrm{g}$ and $0.070 \mathrm{~cm}^{3} / \mathrm{g}$, respectively, for the platelet SBA-15 synthesized with $\mathrm{Zr}(\mathrm{IV})$ ions.

The interaction between P-123 template and the silica framework was examined by thermal analysis (Figure 4). For conventional fiber-shaped SBA-15, a steep weight loss appeared at $170-290{ }^{\circ} \mathrm{C}$ is attributed to the decomposition of P123 triblock copolymer. ${ }^{6}$ For platelet-shaped SBA-15, the weight loss shifts to $240-380{ }^{\circ} \mathrm{C}$, implying that the interaction between P123 and silica framework is stronger when $\mathrm{Zr}(\mathrm{IV})$ ions are present. On the other hand, the $\mathrm{Zr} / \mathrm{Si}$ atomic ratio analyzed by surface sensitive EDX technique was 0.043 and higher than that by ICP-AES $(\mathrm{Zr} / \mathrm{Si}=0.034)$. These results infer that the $\mathrm{Zr}(\mathrm{IV})$ species are probably present on the surface of the silica wall and bind strongly to P123 micelles.

The in situ XRD technique was utilized to study the effect of $\mathrm{Zr}(\mathrm{IV})$ ions on the self-assembly of P123 micelles and silica precursors by using Sychrotron X-ray source at beam line 17A of NSRRC, Taiwan. ${ }^{20 a}$ For the conventional SBA15 with fiberlike morphology, the gel compositions were 0.017:1.0:7.94:221 P123:TEOS: $\mathrm{HCl}: \mathrm{H}_{2} \mathrm{O} .{ }^{6}$ Figure 5a shows that a broad diffraction peak at $2 \theta=0.66^{\circ}$ corresponding to $d$-spacing of $13.4 \mathrm{~nm}$ appeared after TEOS was added for $52.2 \mathrm{~min}$. Meanwhile, white precipitate was observed. Higher-angle diffraction peaks of (110) and (200) planes gradually appeared after about $2 \mathrm{~h}$. These results were similar to those in previous reports. ${ }^{20 \mathrm{~b}, \mathrm{c}}$ For the SBA-15 prepared with $\mathrm{Zr}(\mathrm{IV})$ ions, a diffraction peak at $2 \theta=0.61^{\circ}$ corresponding to $d$-spacing of $14.5 \mathrm{~nm}$ was promptly observed after TEOS was added for $7.3 \mathrm{~min}$ (Figure $5 \mathrm{~b}$ ). The white precipitate was also seen at this moment. The (110) and (200) diffraction peaks appeared after about $30 \mathrm{~min}$. The effect of $\mathrm{Zr} / \mathrm{Si}$ ratio on the time needed for the first appearance of diffreaction peak (designated as $\tau$ ) is shown in Figure 5c. The $\tau$ drops markedly from $52 \mathrm{~min}$ to ca. $20 \mathrm{~min}$ by adding only $2.5 \mathrm{mM}$ of $\mathrm{ZrOCl}_{2}$ in the synthesis solution. With a further increase in the $\mathrm{Zr}(\mathrm{IV})$ concentration, the $\tau$ value decreases gradually and lowers to ca. $7 \mathrm{~min}$ when $12.5 \mathrm{mM}$ of $\mathrm{ZrOCl}_{2}$ is added. These results demonstrate that the formation of ordered mesoporus silica is accelerated by $\mathrm{Zr}(\mathrm{IV})$ ions.

The aggregation of P123 micelles in the synthesis solution before and after the addition of TEOS was studied

(19) (a) Kabalnov, A.; Olsson, U.; Wennerstron, H. J. Phys. Chem. 1995, 99, 6220. (b) Alfredsson, V.; Amenitsch, H.; Kleitz, F.; Linden, M.; Linton, P.; Teixeira, C. V. Stud. Surf. Sci. Catal. 2005, 158, 97. (c) Li, C.; Wang, Y.; Guo, Y.; Liu, X.; Guo, Y.; Zhang, Z.; Wang, Y.; Lu, G. Chem. Mater. 2007, 19, 173.

(20) (a) Liu, M.-C.; Sheu, H.-S.; Cheng, S. Chem. Commun. 2002, 854. (b) Flodstrom, K.; Teixeira, C. V.; Amenitsch, H.; Alfredsson, V.; Linden, M. Langmuir 2004, 20, 4885. (c) Flodstrom, K.; Wennerstrom, H.; Teixeira, C. V.; Amenitsch, H.; Linden, M.; Alfredsson, V. Langmuir 2004, 20, 10311. 

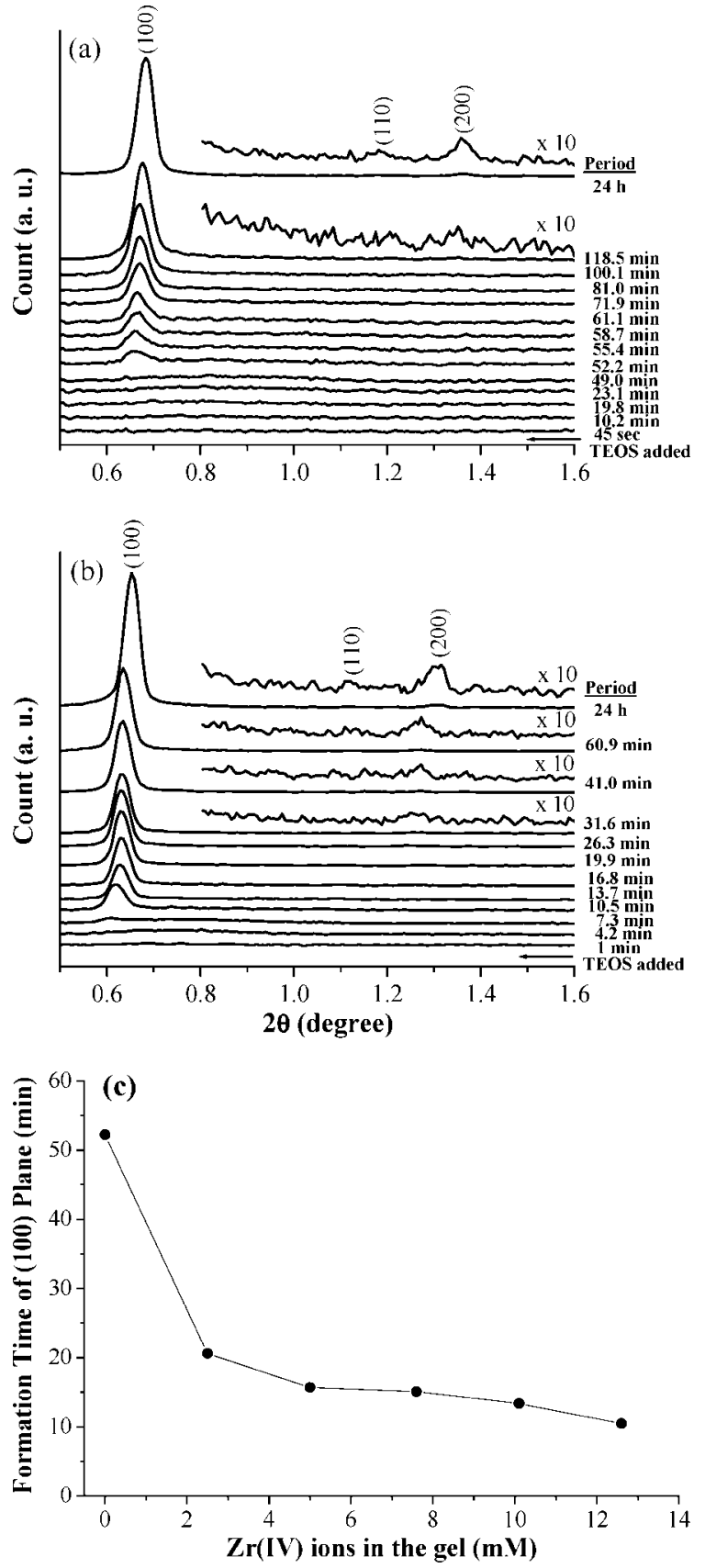

Figure 5. In situ XRD patterns using a synchrotron X-ray radiation source $(\lambda=1.33344 \AA$ ) of SBA-15 prepared (a) without adding $\mathrm{Zr}(\mathrm{IV})$ ions, (b) with $\mathrm{Zr}(\mathrm{IV})$ ions, and (c) the effect of $\mathrm{Zr}(\mathrm{IV})$ concentration on the time $(\tau)$ of first appearance of the diffraction peak.

by TEM microscopy. No mesophase of P123 micelles could be detected in the $\mathrm{P} 123-\mathrm{HCl}-\mathrm{H}_{2} \mathrm{O}$ synthesis solution prior to the addition of TEOS. Because the P123 concentration in the solution was $2.5 \mathrm{wt} \%$ and much higher than the critical micellar concentration $(\mathrm{cmc})$ of P123 molecules $\left(0.025 \mathrm{wt} \%\right.$ at $\left.25^{\circ} \mathrm{C}\right),{ }^{21}$ this result infers that the electron density of P123 micelles is too low to be detected by the electron microscope. The aggregates

(21) (a) Flodstrom, K.; Wennerstrom, H.; Alfredsson, V. Langmuir 2004 20, 680. (b) Linden, M.; Schunk, S. A.; Schuth, F. Angew. Chem., Int. Ed. 1998, 37, 6-821. (c) Ruthstein, S.; Frydman, V.; Kababya, S.; Landau, M.; Goldfarb, D. J. Phys. Chem. B 2003, 107, 1739. (d) Ruthstein, S.; Schmidt, J.; Kesselman, E.; Talmon, Y.; Goldfarb, D. J. Am. Chem. Soc. 2006, 128, 3366. of worm-like P123 micelles of ca. 4-6 nm in diameter became detectable only after TEOS was added. However, the aggregation number and the structure of the micelles could be changed during the drying process when preparing the specimens for TEM.

To avoid the possible interference from drying or the stain agent, we further monitored the self-assembly processes by directing the images of freeze-fracture replication (FFR) with TEM technique. The wet gels collected after various reaction periods were quenched immediately in liquid $\mathrm{N}_{2}$ and the TEM photographs of the replicas were taken. Figure 6 shows that after TEOS was added for $30 \mathrm{~min}$, aggregates in $800 \mathrm{~nm}-2 \mu \mathrm{m}$ with ruptures and worm pores were seen. Further reaction for $1 \mathrm{~h}$, no significant changes in the particle morphology and pore structure were observed. However, pronounced changes were seen after reaction for $1.5 \mathrm{~h}$. The particles turn to short-rod morphology with a thickness in ca. 600 $\mathrm{nm}$ and diameter in $2 \mu \mathrm{m}$. In addition, some of the short rods are interconnected and form longer rods, and wellarranged mesochannels can be seen along the length of the short rods. Further prolonging the reaction to $3 \mathrm{~h}$, the diameter of the rods does not change significantly but the length of the rod increases to micrometer level. It is mentionable that the structures and sizes of the replicas inevitably include the thicknesses of $\mathrm{Pt}-\mathrm{C}$ and $\mathrm{C}$ coverages, which are about 2 and $20 \mathrm{~nm}$, respectively.

In the synthesis solution containing $\mathrm{Zr}$ (IV) ions, the aggregates containing tinny cylinders of $25-50 \mathrm{~nm}$ in diameters dispersed in a linear pattern were observed after TEOS was added for $30 \mathrm{~min}$ (Figure 7). The short rods are likely a result of silica condensation around the threadlike P123 micelles. After another 10 min, platelike particles with ordered mesochannels aligned along the thickness of the platelets were seen. The diameters of the channeling pores were around $10.5 \mathrm{~nm}$. The pore diameter shrank slightly to 8.5-9 $\mathrm{nm}$ due to further silica condensation as the reaction was prolonged. Clearly, the ordered porous structure appeared much faster than that without $\mathrm{Zr}(\mathrm{IV})$. It is also noticeable that no growth of the particles along the channeling direction was seen with the prolongation of the reaction.

Ruthstein and co-workers ${ }^{21 \mathrm{~d}}$ have observed spherical micelles of P123 by direct imaging cryo-TEM experiments after adding tetramethyl orthosilicate (TMOS) as silica source into the P123 solution containing $\mathrm{H}_{3} \mathrm{PO}_{4}$ for $6.5-8.5 \mathrm{~min}$. After $22 \mathrm{~min}$, spherically micelles of $9.7 \pm 1 \mathrm{~nm}$ in average diameter and flexible threadlike micelles of $7.1 \pm 0.9 \mathrm{~nm}$ in diameter and $15-30 \mathrm{~nm}$ in length were reported to coexist. In $\mathrm{HCl}$, the apprearance of spherical and threadlike micelles has been shortened to 5.2 and $14.1 \mathrm{~min}$, respectively. These results are attributed to that the weaker acidity of $\mathrm{H}_{3} \mathrm{PO}_{4}$ makes silica condensation in a slower rate and a relatively longer period is needed to observe the silica coated micelles. As the silica condensation further proceeded, the P123-silica nanocomposite was formed, which transformed gradually to 2D hexagonal arrangement. Again, it took $2 \mathrm{~h}$ in $\mathrm{H}_{3} \mathrm{PO}_{4}$, but only 22 min in $\mathrm{HCl}$. 

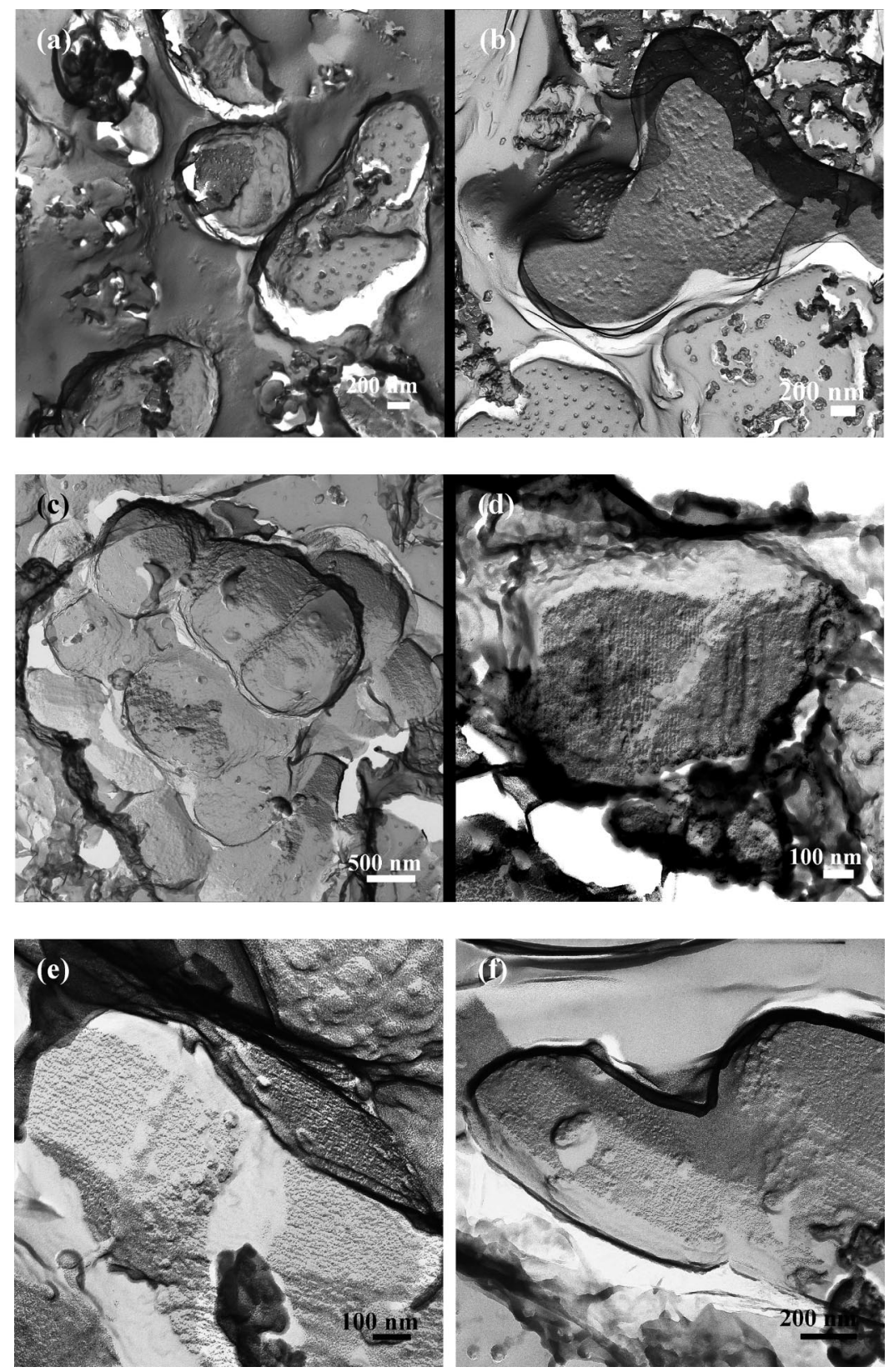

Figure 6. Freeze-fracture replication TEM images of SBA-15 synthesis solution during conventional synthesis process, taken after adding TEOS for (a) 30 min, (b) $1 \mathrm{~h}$, (c, d) $1.5 \mathrm{~h}$, and (e, f) $3 \mathrm{~h}$.

In combination with the results of cryo-TEM studies reported in the literature ${ }^{21 \mathrm{~d}}$ and present freeze-fracture replication TEM and in situ XRD studies, the effect of $\mathrm{Zr}(\mathrm{IV})$ ions on the evolution of mesostructure and morphologies of SBA-15 is summarized in Figure 8. In the early stage of assembly processs, it can be pictured that the threadlike P123 micelles coated with silica are formed after TEOS is introduced into the synthesis solution for about $10 \mathrm{~min}$. As silica condensation proceeds, the disordered stuctures and aggregates of P123-silica nanocomposite materials are formed in the following $20-30 \mathrm{~min}$. As the silicate further condensates around the P123 micelles, the micelles were stretched and aligned in 2D hexagonal arrangement. The short rods interconnect through the ends of the channels and form longer rods along the channeling direction as the reaction prolongs. On the other hand, the silicate condensation around the micelles was accelerated by the presence of
$\mathrm{Zr}(\mathrm{IV})$ ions in the synthesis solution. The plate-shaped SBA15 particles are a result of the quick silicate condensation which also terminates the possibility of interconnection between particles.

$\mathrm{The} \mathrm{Zr}(\mathrm{IV})$ ions probably play two roles in the assembly process. One is the so-called salting-out effect, in which the highly solvated species reduce the cmc value of P123 triblock copolymer and probably also increase the local concentration of TEOS around P123 micelles. As a result, the hydrolysis and condensation of TEOS on P123 micelles are accelerated by adding $\mathrm{Zr}(\mathrm{IV})$ ions in synthesis solution. On the other hand, $\mathrm{Zr}(\mathrm{IV})$ species may interact with the hydrophilic PEO chains of P123 likely through dative bond. That interaction explains that $\mathrm{Zr}$ is mainly present on the surfaces of the pore walls and the observed expansion in the diameter of mesopores of the resultant platelet SBA-15. 

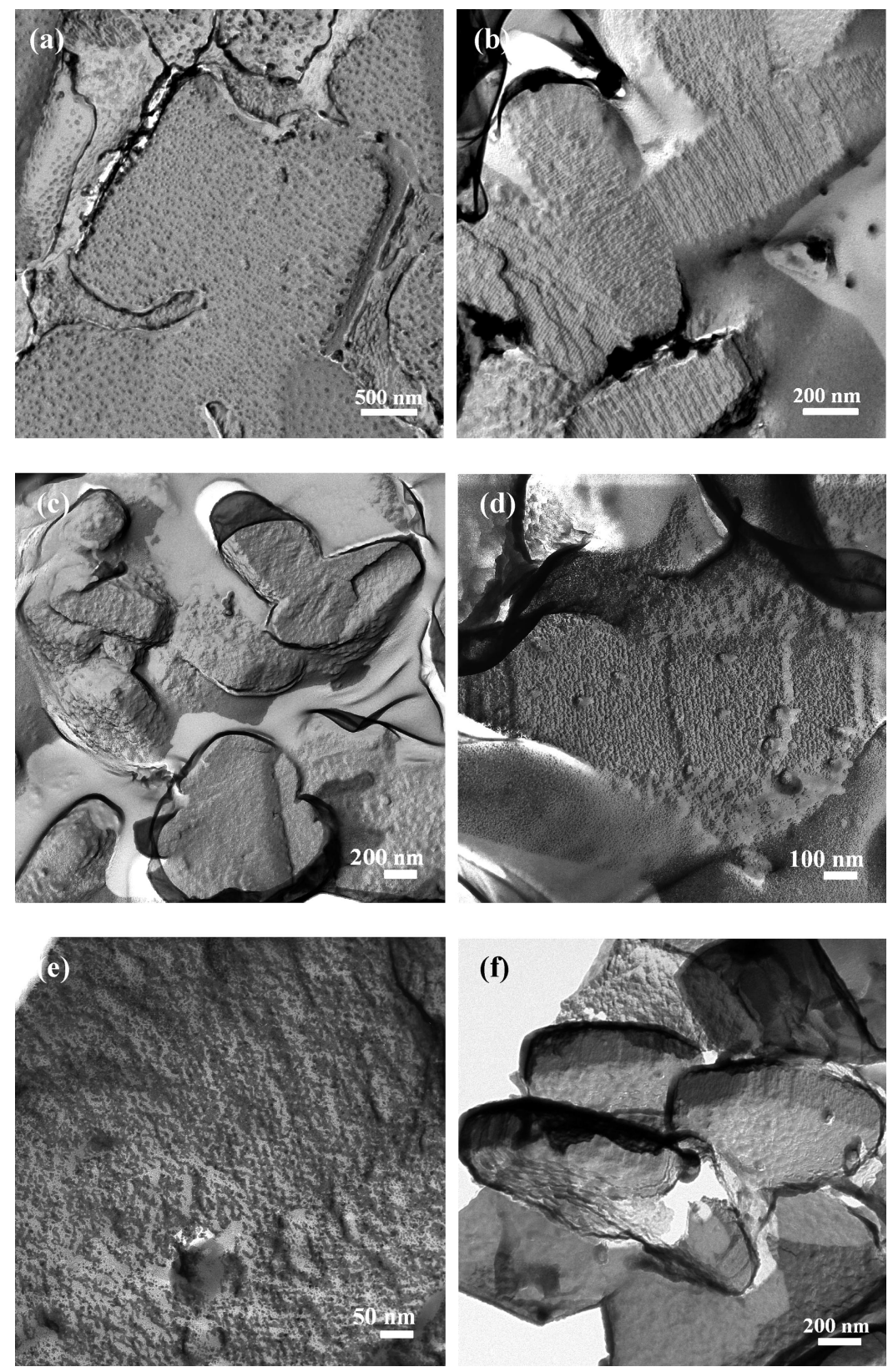

Figure 7. Freeze-fracture replication TEM images of SBA-15 synthesis solution containing Zr(IV) ions, taken after adding TEOS for (a) 30 min, (b) 40 min, (c, d) $1 \mathrm{~h}$, (e) $1.5 \mathrm{~h}$, and (f) $3 \mathrm{~h}$.

The influence of organosilanes on the self-assembly process was also examined by in situ XRD. It was found that the process was seriously impeded if the organic silane and TEOS were mixed simultaneously in one pot (Figure 9a). That is especially pronounced when the organic moieties have lone pair electrons to form dative bonds with $\mathrm{Zr}(\mathrm{IV})$ ions or strongly interact with P123 micelles through hydrogen bonding. As a result, the precipitates without ordering pore arrangement were obtained.

It is well documented that prehydrolysis of TEOS is essential in order to obtain well-ordered SBA-15 materials with high loading of organic functional groups in one pot. $^{22-24}$ The organic functionalized SBA-15 with platelet morphology and short mesochannels were prepared with TEOS prehydrolysis for $1-4 \mathrm{~h}$ and the organosilane/TEOS ratios kept in $10 \mathrm{~mol} \%$. Although both freeze-fracture replication TEM and in situ XRD show that well ordered
2-D hexagonal structures are formed after TEOS is added for $40 \mathrm{~min}$ and $1.5 \mathrm{~h}$ with and without $\mathrm{Zr}$ (IV) ions, respectively, in situ XRD shows that the assembly processes are still perturbed by the introduction of organic silanes. Figure $9 \mathrm{~b}$ shows that a broad diffraction at $2 \theta \approx$ $0.61^{\circ}$ was observed in several minutes in the acidic solution containing TEOS, P123, and $\mathrm{Zr}(\mathrm{IV})$. The peak grew stronger and sharper as the reaction progressed. When methyltriethoxysilane (MTES) was introduced into the synthesis gel after $1 \mathrm{~h}$, the diffraction peak immediately weakened and moved toward higher angle. Nevertheless, the diffraction peak regained its intensity in the next 5 min and grew gradually without moving the position significantly. After TEOS was added for $1.5 \mathrm{~h}$, the (110) and (200) diffraction peaks appeared at $2 \theta \approx 1.13$ and $1.28^{\circ}$. These results indicate that the self-assembly of P123 micelles and TEOS is slightly perturbed by MTES, but 


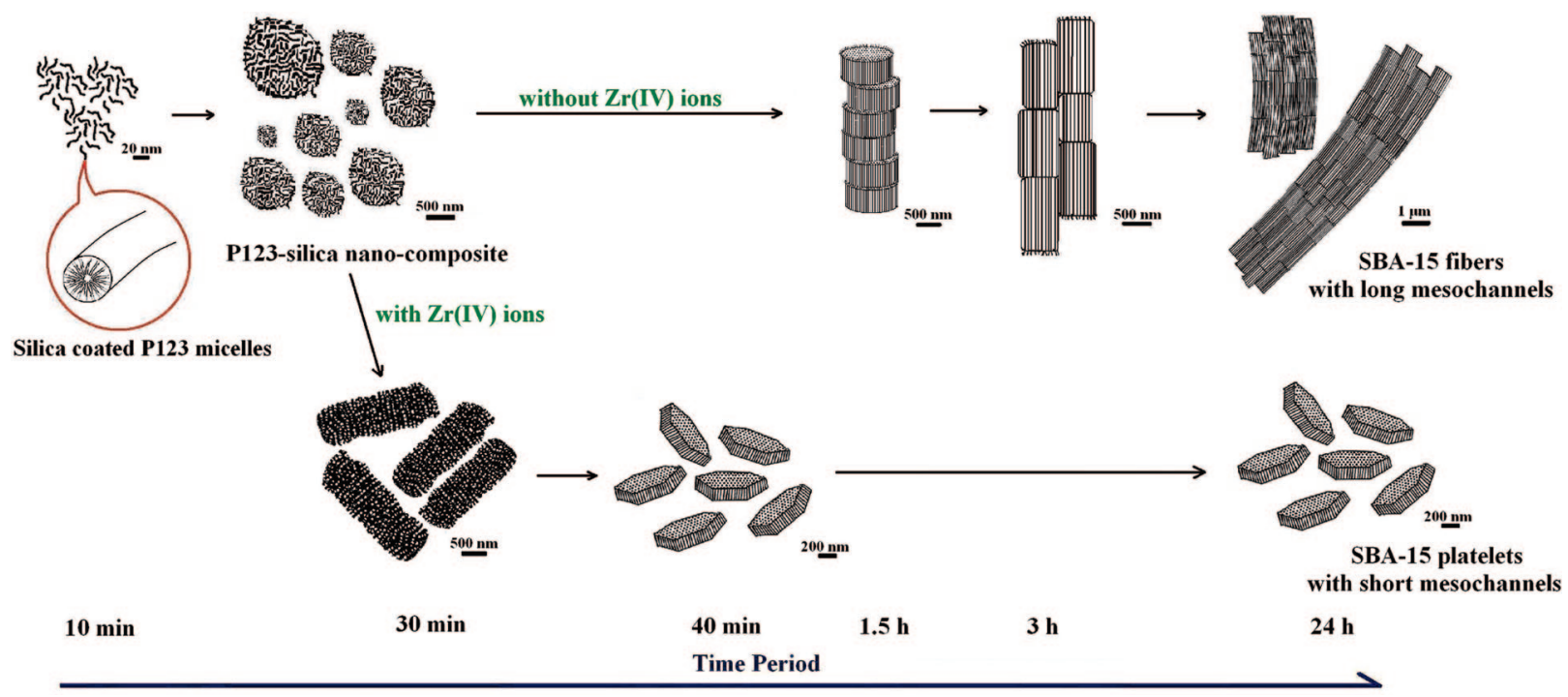

Figure 8. A schematic description of the effect of $\mathrm{Zr}(\mathrm{IV})$ ions on the evolution of mesostructures and morphologies of SBA-15 materials.
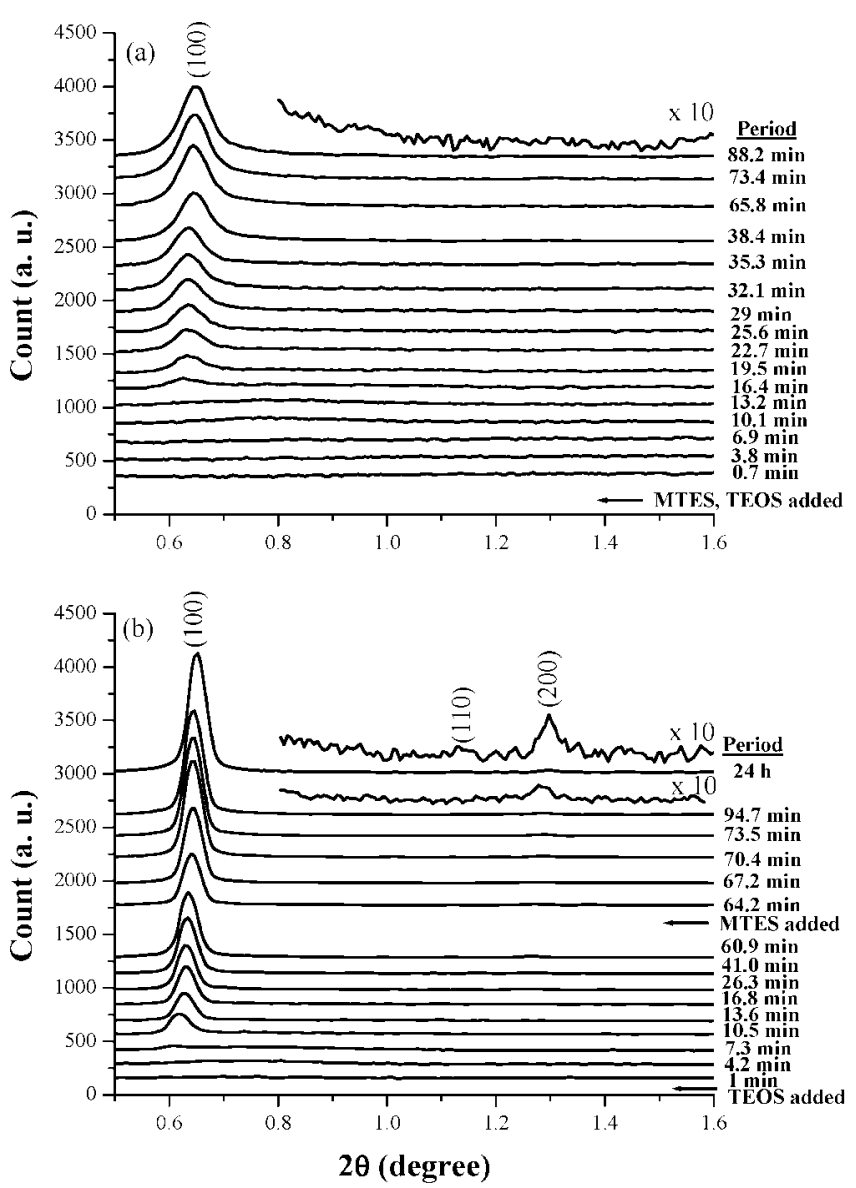

Figure 9. In situ XRD patterns using a synchrotron X-ray radiation source $(\lambda=1.33344 \AA)$ of methyl-functionalized SBA-15 prepared with $\mathrm{Zr}(\mathrm{IV})$ ions: (a) no TEOS prehydrolysis, and (b) TEOS prehydrolysis for $1 \mathrm{~h}$.

adding $\operatorname{Zr}(\mathrm{IV})$ species in the synthesis solution still dominates the rate of mesoporous silica formation.

(22) Corriu, R. J. P.; Mehdi, A.; Reye, C.; Thieuleux, C.; Frenke, A.; Gibaud, A. New. J. Chem. 2004, 28, 156.

(23) Yang, Q.; Liu, J.; Yang, J.; Zhang, L.; Feng, Z.; Zhang, J.; Li, C. Microporous Mesoporous Mater. 2005, 77, 257.

(24) Liu, N.; Assink, R. A.; Smarsly, B.; Brinker, C. J. Chem. Commun. 2003, 1146
The elemental analyses indicated that the FG/Si molar ratios in the solid products were similar to those introduced in the synthesis solutions (Table 1). Moreover, BJH analyses of the $\mathrm{N}_{2}$ sorption isotherms showed that the organic functionalized SBA-15 platelets have smaller pore sizes but thicker pore walls than those of siliceous SBA-15 sample. These results infer that most of the organosilane precursors were incorporated onto the silica framework. In other words, the silicate condensation is still proceeding even the ordered pores are formed, and the reorganization of the silica framework can last longer than a day at reaction temperature of $35^{\circ} \mathrm{C}$.

Solid state ${ }^{13} \mathrm{C}$ and ${ }^{29} \mathrm{Si}$ NMR spectroscopes are the useful tools for characterization of the locally chemical environment of carbon and silicon elements in the mesoporous organosilica materials, such as the bonding of hydrocarbon and the condensation of organosiloxane and siloxane species. ${ }^{22-27}$ Solid-state ${ }^{13} \mathrm{C}\left\{{ }^{1} \mathrm{H}\right\}$ cross-polarization and ${ }^{29} \mathrm{Si}$ MAS NMR spectra of the ethanol extracted platelet SBA-15 with various organic functionalities are shown in Figure 10. In the ${ }^{13} \mathrm{C}$ CP-MAS NMR spectra, the peak at -4.2 ppm corresponds to the $\mathrm{C}$ atom on the $\mathrm{CH}_{3}-\mathrm{Si}$ group, two peaks at 128.2 and $133.7 \mathrm{ppm}$ correspond to $\mathrm{C}$ atoms on the ph-Si groups, and three distinct peaks appeared at 9.6-11.7, 16.4-26.5 and 27.7-47.6 ppm corresponding to the carbon atoms of $\mathrm{Si}-\mathrm{CH}_{2}-\mathrm{CH}_{2}-\mathrm{CH}_{2}-$ groups in sequence from left to right for the propylene-containing functional groups. ${ }^{22-27} \mathrm{Ad}-$ ditional weak peaks at $24,71,74$, and $76 \mathrm{ppm}$ are attributed to the residual P123 template in the material. ${ }^{25}$ The ${ }^{13} \mathrm{C}$ NMR spectra confirmed that the platelet SBA-15 materials are indeed incorporated with various organic functional groups

(25) (a) Yang, C. M.; Zibrowius, B.; Schuth, F. Chem. Commun. 2003, 1772. (b) Yang, C. M.; Zibrowius, B.; Schmidt, W.; Schuth, F. Chem. Mater. 2004, 16, 2918.

(26) Margolese, D.; Melero, J. A.; Christainsen, S. C.; Chmelka, B. F.; Stucky, G. D. Chem. Mater. 2000, 12, 2448.

(27) (a) Wouters, B. H.; Chen, T.; Dewilde, M.; Grobet, P. J. Microporous Mesoporous Mater. 2001, 44-45, 453. (b) Luhmer, M.; d'Espinose, J. B.; Hommel, H.; Legrand, A. P. Magn. Reson. Imaging 1996, 14, 911. 
(a)

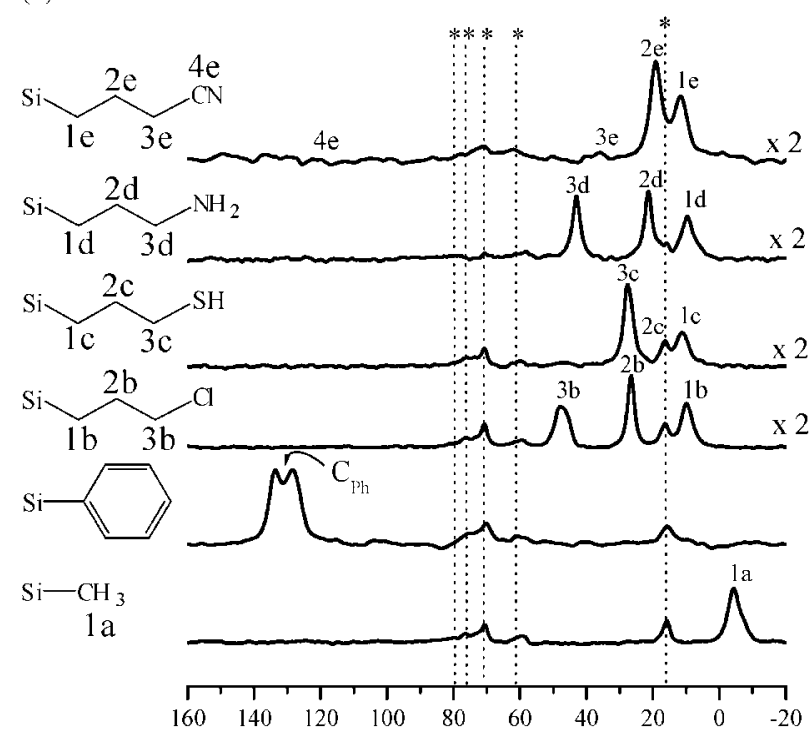

Chemical Shift (ppm) (b)

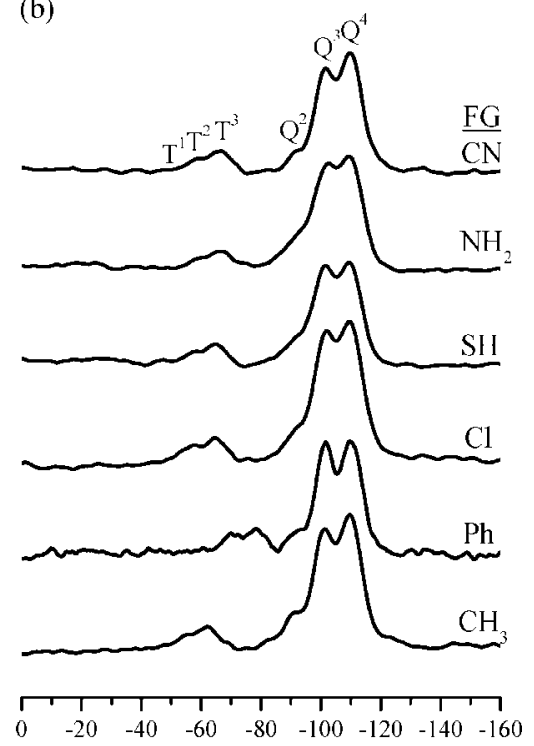

Chemical Shift (ppm)

Figure 10. (a) Solid-state ${ }^{13} \mathrm{C}$ CP-MAS spectra and (b) ${ }^{29} \mathrm{Si} \mathrm{MAS} \mathrm{NMR} \mathrm{spectra} \mathrm{of} \mathrm{various} \mathrm{extracted} \mathrm{organic} \mathrm{functionalized} \mathrm{SBA-15} \mathrm{with} \mathrm{platelet} \mathrm{morphology}$ and short mesochannels; Peaks labeled * correspond to carbon atoms from the P123 residue.

Table 2. Elemental Analyses and Textural Properties of Extracted Organic Functionalized SBA-15 of Fiber Shape and Long Mesochannels

\begin{tabular}{|c|c|c|c|c|c|c|c|c|c|}
\hline \multirow[b]{2}{*}{ functionality } & \multirow[b]{2}{*}{$\mathrm{PT}^{a}(\mathrm{~h})$} & \multicolumn{2}{|c|}{$\mathrm{FG} / \mathrm{Si}$} & \multirow[b]{2}{*}{$a_{0}(\mathrm{~nm})$} & \multirow[b]{2}{*}{$S_{\mathrm{BET}}\left(\mathrm{m}^{2} / \mathrm{g}\right)$} & \multirow[b]{2}{*}{$V_{\text {Total }}\left(\mathrm{cm}^{3} / \mathrm{g}\right)$} & \multirow[b]{2}{*}{$\Phi_{\mathrm{P}}^{c}(\mathrm{~nm})$} & \multirow[b]{2}{*}{$\operatorname{PSD}^{d}(\mathrm{~nm})$} & \multirow[b]{2}{*}{$W^{e}(\mathrm{~nm})$} \\
\hline & & gel & solid $^{b}$ & & & & & & \\
\hline none & 0 & 0 & 0 & 10.6 & 802 & 0.95 & 5.7 & 0.6 & 4.9 \\
\hline $\mathrm{CH}_{3}$ & 2 & 0.091 & 0.095 & 11.7 & 810 & 0.93 & 6.7 & 0.6 & 5.0 \\
\hline$\left(\mathrm{CH}_{2}\right)_{3} \mathrm{Cl}$ & 2 & 0.091 & 0.092 & 10.9 & 659 & 0.67 & 4.8 & 1.1 & 6.1 \\
\hline$\left(\mathrm{CH}_{2}\right)_{3} \mathrm{SH}$ & 2 & 0.091 & 0.087 & 11.6 & 598 & 0.60 & 4.5 & 1.1 & 7.1 \\
\hline$\left(\mathrm{CH}_{2}\right)_{3} \mathrm{NH}_{2}$ & 2 & 0.091 & 0.082 & 12.7 & 677 & 0.85 & 6.4 & 1.2 & 6.3 \\
\hline
\end{tabular}

${ }^{a}$ Prehydrolysis period. ${ }^{b} \mathrm{FG} / \mathrm{Si}$ molar ratios are measured by CHNS elemental analysis. ${ }^{c}$ Pore diameter. ${ }^{d}$ Pore size distribution. ${ }^{e}$ Wall thickness.

and the organic moieties are not decomposed during the preparation procedures.

The ${ }^{29}$ Si MAS NMR spectra of the functionalized SBA15 platelets all have three distinct resonance peaks in upfield corresponding to $\mathrm{Q}^{n}\left(\mathrm{Q}^{n}=\mathrm{Si}(\mathrm{OSi})_{n}(\mathrm{OH})_{4-n}, n=2-4 ; \mathrm{Q}^{4}\right.$ at $-110 \mathrm{ppm}, \mathrm{Q}^{3}$ at $-101 \mathrm{ppm}$, and $\mathrm{Q}^{2}$ at $\left.-91 \mathrm{ppm}\right)$ and three weaker peaks in downfield assigned to $\mathrm{T}^{m}$ $\left(\mathrm{T}^{m}=\mathrm{RSi}(\mathrm{OSi})_{m}(\mathrm{OH})_{3-m}, m=1-3\right)$. The appearance of $\mathrm{T}^{m}$ peaks confirms that the organic silane is incorporated as a part of the silica wall structure. The $\left(\mathrm{Q}^{4} / \mathrm{Q}^{2}+\mathrm{Q}^{3}\right)$ values of organic functionalized SBA-15 platelets are in 1.10-1.24, slightly lower than $1.28-1.36$ for siliceous SBA-15, $6,27,28$ implying that the condensation of the silica framework is less complete in the presence of organic silanes. The $\Sigma \mathrm{T}^{m} /$ $\Sigma \mathrm{Q}^{n}$ values are around $0.086-0.097$, which are consistent with the results of elemental analyses.

Inorganic salts are commonly added into the synthesis solutions in order to obtain well-ordered SBA-15. ${ }^{10,19 b, c, 28-32}$

(28) (a) Chen, S. Y.; Cheng, S. Stud. Surf. Sci. Catal. 2005, 156, 89. (b) Chen, S. Y.; Cheng, S. Chem. Mater. 2007, 19, 3041.

(29) (a) Yu, C.; Tian, B.; Fan, J.; Stucky, G. D.; Zhao, D. J. Am. Chem. Soc. 2002, 124, 4556. (b) Yu, C.; Fan, J.; Tian, B.; Zhao, D.; Stucky, G. D. Adv. Mater. 2002, 14, 1742.

(30) (a) Das, D.; Tsai, C. M.; Cheng, S. Chem. Commun. 1999, 473. (b) Chen, S. Y.; Jang, L. Y.; Cheng, S. J. Phys. Chem. B 2006, 110, 11761.

(31) Flodstrom, K.; Alfredsson, V.; Kallrot, N. J. Am. Chem. Soc. 2003, 125,4402 .
The pore ordering and textural properties of the organic functionalized SBA-15 were indeed markedly improved when $1.5 \mathrm{M} \mathrm{NaCl}$ was added (Table 2). However, SEM images show that the morphology of the resultant SBA-15 materials is fiberlike aggregates with about $500 \mathrm{~nm}$ in diameter and $10 \mu \mathrm{m}$ in length (see the Supporting Information). TEM images show that the mesochannels are aligned along the length of fibers, which is longer than $10 \mu \mathrm{m}$.

The uptakes of new coccine dye (Supporting Information) and octadecane on organic functionalized SBA-15 materials with platelet and fiber morphologies are compared and summarized in Table 3. The uptakes of new coccine on conventional SBA-15 materials are all slightly lower than those over platelet materials. The differences are enlarged when the materials contain organic functional groups, especially phenyl and cyanopropyl groups. It is also noticeable that the absorption capacities of aminopropyl-functionalized SBA-15 toward new coccine are much higher than those over other materials, probably because of the strong hydrogen-bond interaction between the anchored aminopropyl and the sulfate groups on the dye. The adsorption rates of new coccine dye on aminopropyl-functionalized SBA-15

(32) Guo, W.; Park, J. Y.; Oh, M. O.; Jeong, H. W.; Cho, W. J.; Kim, I.; Ha, C. S. Chem. Mater. 2003, 15, 2295. 
Table 3. Adsorption Amounts of New Coccine and Octadecane over Extracted Organic Functionalized SBA-15 with Short and Long Mesochannels $^{a}$

\begin{tabular}{|c|c|c|c|c|}
\hline \multirow[b]{2}{*}{ functionality } & \multicolumn{2}{|c|}{$\begin{array}{c}\text { uptake of new } \\
\text { coccine }(\mathrm{mmol} / \mathrm{g})\end{array}$} & \multicolumn{2}{|c|}{$\begin{array}{c}\text { uptake of } \\
\text { octadecane }(\mathrm{mmol} / \mathrm{g})\end{array}$} \\
\hline & $\begin{array}{c}\text { long } \\
\text { mesochannels }\end{array}$ & $\begin{array}{c}\text { short } \\
\text { mesochannels }\end{array}$ & $\begin{array}{c}\text { long } \\
\text { mesochannels }\end{array}$ & $\begin{array}{c}\text { short } \\
\text { mesochannels }\end{array}$ \\
\hline none & 0.34 & 0.37 & 0.40 & 1.10 \\
\hline $\mathrm{CH}_{3}$ & 0.65 & 0.93 & 7.83 & 8.04 \\
\hline $\mathrm{Ph}$ & 0.71 & 1.18 & 5.90 & 7.69 \\
\hline$\left(\mathrm{CH}_{2}\right)_{3} \mathrm{Cl}$ & 0.73 & 0.93 & 5.00 & 7.77 \\
\hline$\left(\mathrm{CH}_{2}\right)_{3} \mathrm{SH}$ & 1.11 & 1.35 & 5.49 & 6.19 \\
\hline$\left(\mathrm{CH}_{2}\right)_{3} \mathrm{NH}_{2}$ & 14.3 & 15.4 & 2.44 & 5.25 \\
\hline$\left(\mathrm{CH}_{2}\right)_{3} \mathrm{CN}$ & 0.77 & 1.23 & 5.00 & 5.75 \\
\hline
\end{tabular}

${ }^{a}$ Adsorption experiments were carried out at RT for 1 day; new coccine in ethanol, octadecane in hexane.

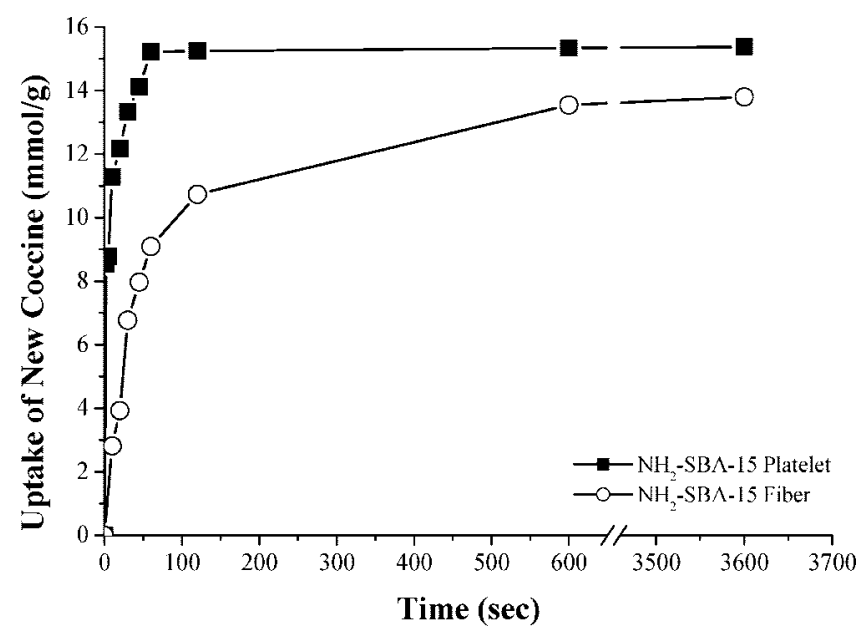

Figure 11. Uptakes of new coccine as a function of adsorption period at RT over extracted $\mathrm{NH}_{2}\left(\mathrm{CH}_{2}\right)_{3}$-functionalized SBA-15 with short (ם) and long $(\mathrm{O})$ mesochannels.

with short and long mesochannels were compared in order to understand the effect of pore length on the molecular diffusivity through the channels. Figure 11 shows that it takes ca. 10 min for the adsorption of new coccine dye to reach equilibrium on the fiber material, whereas it takes only 1 min on the platelet material. These results demonstrate that the short mesochannels facilitate the diffusion of the bulky dye molecules through the channels. Moreover, the higher uptake of new coccine dye by SBA-15 with platelet morphology and short mesochannels is attributed to the smaller possibility of pore-blockage in comparison to that with long mesochannels.

\section{Conclusions}

Large pore SBA-15 silica of platelet shape and very short mesochannels in 150-350 $\mathrm{nm}$ was developed by introducing a small amount of $\mathrm{Zr}(\mathrm{IV})$ ions in the synthesis solution. The in situ XRD and freeze-fracture replication cryo-TEM are powerful techniques to study the self-assembly process of mesoporous materials. The platelet SBA-15 with short mesochannels was formed due to the fast self-assembly of P123 micelles and TEOS accelerated by the $\mathrm{Zr}(\mathrm{IV})$ ions in the synthesis solution. With the aid of TEOS prehydrolysis, this synthesis route could be easily extended to prepare various organic functionalized SBA-15 materials with platelet morphology and short mesochannels. These materials are superior to the conventional SBA-15 of rod or fiber morphologies in facilitating molecular diffusion and less possibility of pore blockage when used in the sorption or reactions of bulky molecules.

Acknowledgment. This work was supported by National Science Council, the Ministry of Education, Taiwan, and Taiwan Textile Research Institute. S.Y.C. thanks C.-W. Lu of the Instrumentation Center, National Taiwan University, for CHNS analysis experiments, and C.-N. Ke of National Tsing-Hua University for the ICP-AES experiments.

Supporting Information Available: Figures S1-S4 and additional experimental details (PDF). This material is available free of charge via the Internet at http://pubs.acs.org.

CM703500C 